\title{
Improving Students' English Skill through Teaching Literature as its Unique Discourse
}

\author{
Suatmo Pantja Putra \\ Universitas Merdeka Malang \\ pancaputra234@gmail.com
}

\begin{abstract}
This study presents an analysis of the teaching literature. Approaches to literature teaching seem to be much influenced by current approaches to both language and education. There seems, however, to be a tendency to treat literature as merely another subject on the curriculum. Such a tendency has ultimately led to the neglect of features which mark literature as a discourse and an area of study demanding different techniques of description and different pedagogical approaches. Further, it is often assumed that principles formulated for education in general, or for the teaching of foreign languages in particular, can be extended unchanged to the literature class, on the assumptions that it is a subject of the curriculum and an instance of language use. Yet, it may not be the real case. Social uses of language demand rapid response and intensive interaction. Therefore, in teaching of a foreign language, there are good reasons to encourage constant student interaction and reaction toward their engagement in literary world.
\end{abstract}

Keywords: English language, Discourse, Literature, Unique.

The development of linguistics in general and applied linguistics in particular has shown a considerable growth of interest in Discourse Analysis, the study of how stretches of language take on meaning, purpose, and unity for their users. In the later development, Discourse Analysis has focused very much upon the social nature of communication, emphasizing contextual aspects of meaning which are interactive and negotiated, determined by the social relations and identities of the participants in communication. Such an approach has given significant influences on the language teaching by focusing much on the so-called communicative approach. Which is also influential in the formation of this view has been the Hallidayan conception of language as a social semiotic and the belief that the function of discourse is a blend of the interpersonal and ideational.

The discourse analyst's interest in literature is suggested not only because of its potential to augment the better understanding of discourse in general, but also by its relevance to education. The study of literature has become a substantial part of the curriculum in both first and second languages education. However, there seems to be a consensus in the Discourse Analysis considering that literature is primarily a mode of social interaction, reflecting and 
creating its own institutions and power relations. In this way, there is nothing distinctive about either the language of literary discourse or its representations of the world. It also seems to suggest that some texts become literary when presented as such by institutions or when read in certain ways by readers. Meanwhile, which texts these are will thus always be relative to a specific social milieu.

Such an approach has developed in understandable reactions against other view of literature. Firstly the approach has rejected the idea that literariness resides in a particular use of language, that it is - in other words - a feature of text rather than discourse. This view is hardly tenable, for a number of reasons which have been pointed out. Taking a canon of literally works as a whole, one would be hard - pressed to pinpoint any particular uses of language which are common to all of them. Many literary works, in the contrast, seem pointedly to borrow the language of non-literary discourse. Even in the case of the short lyric poem, the linguistic features which seem to be distinctive such as parallelism and creative deviation are usually found in supposedly non-literary discourses such as advertisements, songs, nursery, rhymes, political speeches, chants and prayers to make it convincing.

A purely linguistic approach can lead to a mechanistic and soulless description of literary texts which leaves the individual reader and the relevance of literature to his or her world, completely out of account. However, it should be noted here that literary language should be admitted as having unique distinctive characteristics in its system as a part of the literary code. Literary language is different from the scientific language in that the latter is reverential, that the object referred (referent) fits for the sign. In literature, a rose does not always refer to the flower, but it can mean 'a woman' just like in Robert Burns' lyric "my love is like a red, red rose". In differentiating the language of literature and the daily languages Jakobson (1960) suggested that the literary language emphasizes the paradigmatic (selection) aspect rather than syntagmatic (combination) aspect. The illustration can be seen as:

\section{Figure 1}

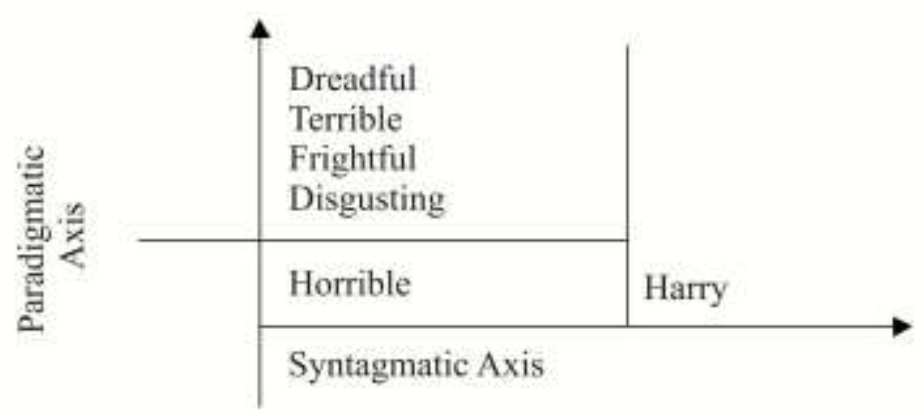

Hence, in literature where paradigmatic is more stressed, a writer will not use all of the adjectives provides although syntactically acceptable, instead, he will choose "Horrible" as the modifier of 'Harry' because of the poetic device of paronomasia (Horri - Harry) 
Secondly, the approach has rejected the idea that through literature a particularly perceptive or accurate view of the world is somehow transmitted to the reader with an overall improving effect, either moral or intellectual. This view, in addition to the role of moral tutor or vicarious experience, has a number of weaknesses which can be revealed by both theory and direct experience. On the theoretical side it subscribes to a very simple transmission view of communication and ignores the problem of how superior perception or judgment, if authors do possess these qualities, is conveyed through language. In addition, experience tells us that there and whose authors were anything but exemplary individuals. In pedagogy, this approach can lead to a rather patronizing morality, a hero - worshipping of authors and a lack of emphasis on the pleasures of literature. Thus, in treating literature, it should be remembered that the world offered in literature is different from reality in common sense because literary world is the secondary model of the world. While the truth, according to spat (in Fokkema and Kunne - Ibsch, 1998) is the third type of truth namely the 'poetic truth' different from the transcendental and the logical truth. This explains the acceptability of certain texts to the readers although they inform the latter with fantastic and fictional things for example a speaking horse in Tolstoy's Kholstomer.

Thirdly, the approach has rejected the idea of literature as a canon of texts interpreted in ways which clearly reflect the value and the identity of a particular nation or social class. This view reduces what could be an instrument of understanding and tolerance between peoples to one which reinforces prejudice. Its pedagogical effects are harmful when a canon interpreted in ways which reflect their own values. It denies the ability of literature to allow them access to ways of seeing which are not theirs.

The rejection of these views, each regarding literature as a discourse with its own distinctive features, has been strengthened by growing doubts about the validity of a literary canon; a body of texts, clearly circumscribed and separable from others, which are generally agreed to constitute 'literature'. The first source of this doubt has been the growing realization that 'Literature' as conceived in contemporary Western society, is a fairly modern invention (William 1983; Foucault, 1979). The second is that the contents of the canon - exactly which texts are deemed to be literature - will vary from age to age and place to place. As the notion of a fixed and unproblematic canon is so central to the literature curriculum, these doubts have either been vituperatively rejected by literature teachers and course designers and have caused a crisis of confidence. The borders between literature and non - literature have become vague and confused, and there seems little left to distinguish the study of literature from the study of language and communication in general.

The force of these arguments against the nation of literature as a fixed or easily identifiable body of texts cannot be denied and it would be naïve not to take them into account. It is obvious that literary canon is relative to a particular time and place, and a particular, socially defined, group of readers. Yet, despite the coldly convincing rigor of the social approach and the validity of the points which it raises, there are elements which it leaves out of account. It is not that the social approach, with its emphasis on the social relativity of literary judgments, is wrong 
but rather that it is incomplete. In addition, like the reigning literary ideologies which it overturned in its day, it too is now in danger of becoming stifling and dogmatic. Too much emphasis on the social relativity of literature may deny the fact that the people often do seem to find something accessible, beautiful, understandable, enjoyable, and uplifting when they reach out to the literary traditions of societies and social groups which are not their own. Many readers can also recognize in those traditions a common experience which cuts across the boundaries of nation, culture and history.

In widely differing social contents, there seems to happen a paradox by the contradiction between the apparent usefulness of literary works and the high value placed upon them. Though such texts may incidentally offer readers information, or create social relations and institutions, this does not seem to be the primary motivation for either the writing or the reading of literature. On the contrary, literary texts, in all kinds of societies, often tell readers at great length of worlds and people who do not exist, of emotions and experiences which do not affect the readers. They dwell at length on the facts which readers have known (death is sad, nature is beautiful, love is joyful, and so on), or they create patterns and play with expectations for no apparent reason at all.

\section{THE IMPLICATION ON THE TEACHING OF LITERATURE}

Approaches to literature teaching seem to be much influenced by current approaches to both language and education. There seems, however, to be a tendency to treat literature as just another use of language and literature study as just another subject on the curriculum. Such a tendency has ultimately led to the neglect of features which mark literature as a discourse and an area of study demanding different techniques of description and different pedagogical approaches. Under the influence of ideas from language pedagogy, the retreat in literary study from an emphasis on linguistics and textual form has been hastened by the general shift of attention (Hymes, 1972) from what is possible in communication to what is appropriate or what is performed. In the foreign language classroom where literature is introduced as a means of furthering language development, literary teaching has been influenced by attention to meaning rather than form.

In all of this, one could see the confusing issues in the teaching of language with issues in the teaching of literature. It is often assumed that principles formulated for education in general, or for the teaching of foreign languages in particular, can be extended unchanged to the literature class, on the assumptions that it is a subject of the curriculum and an instance of language use. Yet, it may not be the real case since social uses of language demand rapid response and intensive interaction. Therefore, in the teaching of a foreign language, there are good reasons to encourage constant student interaction and reaction. Similarly, in the interests of fast and efficient communication, there is an argument for concentration of higher - level predictive 
structures. However, these principles may not necessarily be transferable to the literature class, at least where literature is studied as literature rather than as a way of improving language.

The literary experience in relation to the secondary model of the world is one which demands the individual reader to withdraw from the world of social and practical necessity than plague into it. Such an experience, unfortunately, may not be suited to an educational environment at all since it is as much about rejecting social values as assimilating them. Given that the study of literature does form part of the curriculum, it demands very careful and responsible treatment for some reasons.

First, literary text deautomatized the recipient's relation to reality (Posner, 1982). In relation to the schema theory, literary text is characterized by its power of changing the readers' schemata (Cook, 1994). Literary text deautomatized readers' relation to their textual, linguistic, and world existing schema. In reading texts such as Coleridge's Lyrical Ballads which aimed to disrupt norms of both poetic language and poetic subject - matter, a reader must be ready to entail an acceptance of the new attitude toward language and text. Similarly, in reading Tolstoy's Kholstomer, a reader must be ready to accept a new experience of witnessing a horse speaking like a human being. Meanwhile, the textual knowledge such as a phenomenon in which is more enforced by the looseness of faith to convention in literature suggests that the Russian's concept of 'Canonization of Junior Branch' as the new tradition replaces the former.

Secondly, in relation to the top down approach of discourse processing which shows how expectations influence or even supply understanding, literature offers different kind of the relationship between the top and bottom. In literary study it is not enough to see how conventional expectations predict what will happen but also how deviation from expectation rebounds upon and changes the very predictive structures which literary forms reject. Knowledge of the larger social structures created through discourse is necessary for conventional and conformists language behavior but it is through manipulation of detail that the individuals is able to move beyond them and gain freedom from the constraints they impose. Attention to the larger structures is a first step, and certainly an essential one to a student seeking to understand an unfamiliar culture, but a second step is to disrupt or change these structures and this will demand use and understanding of inappropriate, innovative, never - before - performed manipulations of to code. In this way, grammar and textual form, far from being the tools of repression, are the guarantors of freedom. In literature, the case is more obvious. Students need the knowledge of the literary canon as the foundation of the predictive structures by which they can adapt to any deviation taking place during the learning.

Third, to be always asking students for their reactions and asking them to share these reactions with others may stifle the whole mental process which literature can stimulate. This is especially crucial since literary experience is not associated with any particular text, but with the interaction of text and individual. Certain works on the syllabus, however 'great' may simply not affect a particular reader, and this should be respected. Hence, a teacher is person who believes 
that the experiences he or she has found valuable may be so to others, and who, consequently is to the extraordinary effects of explanation of the tradition and language within which they exist, and form whose norms they may deviate.

However, this demands a decision for applying the teacher - centered method which should be admitted as 'unpopular today since it seems to be very authoritarian (Clark, 1987; White, 1988). In fact, this is not necessarily true. The teacher - centered classroom can create a liberating environment for students, while the student centered classroom can be the vehicle for an insidious authoritarianism and also, if it imposes western educational ideas upon other educational traditions, for cultural chauvinism (O'Neill, 1991). Although in any approach, some classes are inevitably boring for some students, the association of a teacher - centered approach with intellectual tedium contradicts many people's experience. Indeed, the act of silent and solitary reading, so often associated with personal and intellectual development, is an extreme example of allowing another person to do all the talking. For the silent and outwardly passive reader, like the student listening in class, may inwardly be experiencing a mental revolution. This is very often the case in the reading of literature.

In literature teaching there is an additional justification for a degree of teacher centeredness. Literary effect is achieved through deviation from an established literary tradition, a knowledge of that tradition (canon) will be needed by students before they can experience that effect. Time will need to be given to the transmission of knowledge of the canon. An angry reaction this view has rightly been provoked by the specific canons that have been presented by educational establishments. This is particular true where the canon is a national one. The association of a literary canon with the tradition of a nation state often partakes of all the arrogance and militarism which is part and parcel of the nation state often partakes of all the arrogance and militarism which is part and parcel of the nationalism it perpetuates. If often rides roughshod over the literary traditions of immigrant and minority communities within the nation, while also diminishing the traditions of other nations.

In the colonial or post - colonial situation, it is often imposed upon nations with exiting or emerging traditions of their own. Such a narrow approach to the construction of a canon is quite at odds with the civilizing effect of literature, which can stress the commonality rather than the particularity of the human condition, or, where it does associate with a particular culture, is unlikely to do so along boundaries conterminous with those of the politically defined nation. The narrow- minded notion of 'a national canon' has perhaps been instrumental in the declining popularity of the nation that literature teaching should present any canon at all. Yet, opposition to a particular canon should not lead teachers to be oblivious to the way on which the literary discourse operates within and achieves effect through, its conformity to, or deviation from, a particular tradition. 


\section{PLANNING LITERATURE PROGRAM}

Literature program is normally aimed at fulfilling four major objectives namely:

1. Discovering delight in great books (great literary works)

2. Interpreting literature

3. Developing literary awareness

4. Developing appreciation for literature

In universities, the four objectives are assumed to be the main targets of literature program. Students should be able to enjoy literary works, interpret them before finally developing in themselves literary awareness and ability to appreciate literature as a whole. Here a teacher may see the complicated task; on one side students are expected to have many opportunities to experiences and enjoy literature, on the other side teachers should view literature as a content subject to be taught as a discipline. Therefore, good literature programs do not happen without real planning and commitment by the faculty. Each faculty needs to develop a literature program based upon their knowledge of the values of literature for the students, the needs and the characteristics of the students, knowledge of the learning process and a thorough understanding of literature. There are some steps to be taken in planning literature program.

\section{DETERMINING THE STUDENTS' BACKGROUND IN LITERATURE}

In planning a literature program, the consideration must be given on what has been the students' previous experience with literature. Teachers may take an informal survey or inventory of their students' background in literature. They may construct their own or use those which have already been published. These inventories are not tests of the students' literary knowledge but simply that the name implies an informal survey to see what kind of exposure the students' have had to literature. The result of these inventories would provide the teacher with some bases for knowing the literary background of the students. Identifying some of the gaps in the students' exposure to literature would be helpful in planning a literature program for them especially in the effort of providing sufficient needed schemata.

\section{ORGANIZING THE CURRICULUM}

Each faculty should be free to plan their own literature programs. However, it is necessary to provide for a balance in literature between the old and the new, prose and poetry, fiction and the nonfiction, realism and fantasy, and fiction with historical and contemporary setting. In planning the curriculum some agreement should be made by the teachers and librarians concerning a basic list of materials that provides these balances. There should also be a balance between opportunities for wide reading and for small group in-depth reading. 
The study of literature may be organized around authors, genres, content or themes. Once the teacher is knowledgeable about books, it is easy to build the schemata in the students' mind. Throughout the whole semester, students will have no deal with the enjoyment, interpretation and discussion of the craft of the writing to develop their literary awareness and appreciation. For the real beginners (students with no previous experience with literature), the curriculum can be organized by using a thematic approach. Thus materials are chosen in terms of the theme; love, friendship and so on. Yet, the teacher should still provide students with basic knowledge concerning the textual tradition the language, and the general thing about the texts chosen.

\section{EVALUATING THE LITERATURE PROGRAM}

There are some categories that can be used in the evaluation of literature program. One of the categories that can be used is suggested by Bloom (in Moody, 1971). Bloom classified the learning output into three domains; cognitive, affective and psychomotor. In the case of literary teaching, Moody (1971) further suggested four categories; informative, conceptive, perspective and appreciative.

In evaluating the cognitive domain of learning output, Tuckman $(1975 ; 26-27)$ proposed six levels.

a) Memorization: the evaluation is concerned with definition, description, the naming of an object, naming the works and writers and so on.

b) Understanding: such an evaluation is concerned with students' literary awareness about the literary convention and interpretation.

c) Application: the evaluation demands the students to play a simulation game such as demonstration, modification, and operation of a style and so on.

d) Analysis: the evaluation is directed toward the detailed analysis of the elements of literary texts and the interrelationship.

e) Synthesis: students are expected to see the universal common pattern among works labeled less than one tradition such as works of Elizabethan period and so on.

f) Evaluation: students are directed to give their own judgments on the value of the text.

\section{REFERENCES}

Clark, J. (1987). Curriculum Renewal in School Foreign Language Learning. Oxford: Oxford University Press. 
Cook, G. (1994). Discourse and Literature: The Interplay of Form and Mind. Oxford: Oxford University Press.

Fokkema. D.W and Kunne-Ibsch, E. (1998). Theories of Literature in the Twentieth Century. Trans, by Praptahadiraja \& Silaban. Jakarta: Gramedia.

Foucault, M. (1979). What is an author? In J.V. Harari (Ed.), Textual strategies: Perspectives in Post-Structuralist Criticism. London: Longman.

Hymes, D. (1972). On Communicative Competence. In J.B. Pride and I. Holmes (eds.) Sociolinguistics: Selected Reading. Harmondsworth: Penguin.

Jakobson, R. (1960). Closing Statement: Linguistics and Poetics. In T. A.. Sebeok (Ed.) Style in Language. Cambridge, MA: The MIT. Press.

Moody, H.L.B. (1971). The Teaching of Literature in Developing Countries. London, Longman Group Ltd.

O'Neill, R. (1991). The Plausible Myth of Learner-Centeredness or the Importance of Doing Ordinary Things Well. ELT Jounals 45/4:23-305.

Tuckman, B. W. (1975). Measuring Educational Outcomes: Fundamentals of Testing. New York: Harcourt Brace Jovanovich.

White, R.V. (1988). The ELT Curriculum. Oxford: Blackwell

William, R. (1983). Keywords: A Vocabulary of Culture and Society. London: Fontana. 